\title{
Aerodynamic optimisation of Formula student vehicle using computational fluid dynamics
}

\author{
Frankie F. Jackson, University of Huddersfield
}

Frankie.Jackson@hud.ac.uk

Accepted date: 08/11/2017

Published date: 21/02/2018

\begin{abstract}
This work aims to improve the external aerodynamic characteristics of the 2017 University of Huddersfield Formula student vehicle. To improve dynamic performance in the student events, a multiple-element rear wing was developed, which incorporated adjustable elements to constitute a drag reduction system (DRS). A numerical modelling approach was adopted to produce a suitable design. A simplified model of the vehicle was created to obtain baseline coefficients of lift $\left(\mathrm{C}_{\mathrm{L}}\right)$ and drag $\left(C_{D}\right)$. The rear wing was optimised to find the peak configuration generating maximum downforce. The results show that the incorporated rear wing improved the vehicle's $C_{L}$ from 0.21 acting in the positive $Y$ axis (lift) to 1.15 acting in the negative $Y$ axis (downforce), whereas the $C_{D}$ increased from 0.71 to 1.21. However, the DRS configuration reduced the $C_{D}$ to 0.79 . Using the obtained lift and drag coefficients, vehicle performance was estimated, such as maximum cornering speed, straight-line top speed and straight-line acceleration capabilities. The rear wing improved the theoretical maximum cornering speed by $3.1 \%$ for a corner radius of $13 \mathrm{~m}$. The DRS increased the theoretical top speed by $18.2 \%$ compared to a fixed wing configuration. Acceleration potential increased by $15.7 \%$ at $25 \mathrm{~m} / \mathrm{s}$ with the DRS open. The final section of the study used an online simulator (FSAESim) to make
\end{abstract}


predictions of the acceleration event time, which were compared to the track results from the 2017 Hungary student event. The results showed a 97\% similarity.

\section{Keywords}

Vehicle aerodynamics, Formula student, CFD, rear wing, drag reduction system

\section{Acknowledgments}

I would like to thank my final year project supervisor Dr Viacheslav Stetsyuk. His expertise, guidance and feedback were most useful in completing my final year project and his continued support and contribution towards this paper have been immensely valuable. I would also like to express my gratitude to Dr Krzysztof Kubiak for his help and guidance through my final year and his continued support following the completion of my degree. Finally, I would like to thank the 2017 University of Huddersfield Formula Student team for the hard work and long hours that each member contributed towards developing the vehicle with its first aerodynamic package. 


\section{Introduction}

The Formula SAE (Society of Automotive Engineers) is a motorsport event first introduced in 1981 (IMechE, 2017a) that consists of university teams designing and building single-seated race cars to compete in a series of events. Teams are expected to compete in two main areas. Static events comprise design cost and sustainability with business presentation, technical and safety scrutineering, tilt test and brake and noise test. Dynamic events comprise skid pad (figure of eight), sprint, acceleration, endurance and fuel economy (IMechE, 2017b). Teams are awarded points for their performance in each of these categories. To achieve the highest points possible, each aspect of the car must be designed with performance and cost taken into consideration. Aerodynamics in motorsport is now a fundamental aspect of producing a competitive design. The successful implementation of aerodynamic devices in vehicles, first seen in 1960 (Katz, 1995), has enabled increased cornering speeds and subsequent decreased lap times. In the context of the student event, the winning teams from 2012 to 2016 all had aerodynamic devices fitted to their vehicles (Table 1) and, therefore, the 2017 University of Huddersfield team had decided to adopt its first full aerodynamic package. The rules governing the student events also allow relative aerodynamic design freedom, such that movable aerodynamic devices are still permitted, allowing the incorporation of DRS. See Appendix 1 for the nomenclature. 


\section{Table 1}

Previous winning teams of the Formula student UK event from 2012 to 2016.

Retrieved from http://www.imeche.org/events/formula-student/previous-events

\begin{tabular}{|l|l|l|}
\hline Year & Winning Team (UK Event) & Aero-Package \\
\hline 2016 & University of Stuttgart & Active rear wing \\
\hline 2015 & TU Delft & Active rear wing \\
\hline 2014 & TU Delft & Active rear wing \\
\hline 2013 & ETH Zurich & Static aero \\
\hline 2012 & Chalmers UT & Static aero \\
\hline
\end{tabular}

Methods for developing aerodynamic components can include wind tunnel testing of both scaled-down and full-size models, as well as track testing. However, this is often time and cost intensive. Due to an ongoing increase in computing performance and developments in numerical analysis, computational fluid dynamics (CFD) is becoming an ever more crucial tool in automotive design. The CFD design approach has been used by teams such as KTH - Royal Institute of Technology to aid in designing the full vehicle aerodynamic package (Dahlberg, 2014). The work presented in Dahlberg's thesis used the ANSYS Fluent@ CFD package to optimise the design of the diffuser, front wing and rear wing. Additionally, Leitl and Dürnberger (2009) used ANSYS CFX@ to compare two Formula Student vehicle concepts.

The values obtained from the CFD simulations are often used to make performance predictions. Work conducted by Merkel (2013) made predictions of vehicle acceleration with the implementation of active aerodynamics. 
The aim of the present work was to improve the aerodynamic characteristics of the 2017 Formula Student vehicle by using CFD and to describe a unique methodology to calculate traction-limited acceleration. The main objective, therefore, was to develop a multiple-element rear wing with adjustable rear elements, which could provide high levels of downforce to aid with cornering speed capability as well as having a reduced drag configuration to aid in straight-line acceleration. The CFD solver used in this work was ANSYS CFX@. ANSYS CFX@ is a finite volume solver that uses an unstructured grid. In this work, Reynolds-averaged Navier-Stokes (RANS) equations were solved with the k- $\varepsilon$ turbulence model for the $-\rho \overline{u^{\prime}{ }_{l} u^{\prime}}$ term (Eq. 1).

\section{Figure 1}

Final vehicle assembly with implemented aerodynamic devices (left) compared with final vehicle CAD model (right) with additional aerodynamic devices comprising; front wing, side pods and diffuser
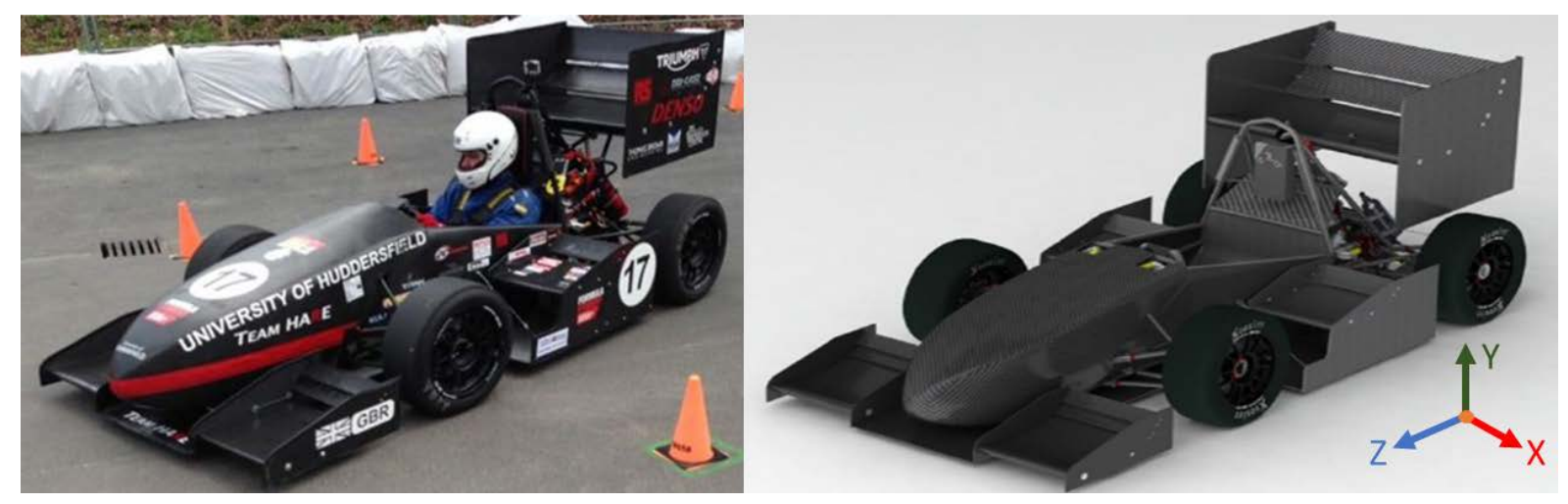

\section{Numerical modelling}

As the vehicle is travelling at relatively low speeds (less than $0.3 \mathrm{Mach}$ ), the simplifying assumption of incompressible flow can be made as the effects on results will be negligible (Versteeg \& Malalasekera, 2007). The effects of temperature change are 
also assumed to be negligible, and thus the problem is treated as isothermal. The governing RANS equations can be written in Cartesian tensor notation as follows:

$$
\rho\left(\frac{\partial \bar{U}_{l}}{\partial t}+\bar{U}_{j} \frac{\partial \bar{U}_{i}}{\partial x_{j}}\right)=-\frac{\partial \bar{P}}{\partial x_{i}}+\frac{\partial}{\partial x_{j}}\left(\mu \frac{\partial \bar{U}_{i}}{\partial x_{j}}-\rho \overline{u^{\prime}{ }_{\imath} u_{j}^{\prime}}\right)
$$

where $\rho$ is the density, $P$ is the pressure, $t$ is the time, $U$ is the mean velocity, $\mu$ is the viscosity and $x$ is a position vector. The last term on the right-hand side requires further modelling. This is known as the closure problem and is the subject of turbulence modelling. In this work, the last term was modelled using the standard k- $\varepsilon$ turbulence model as it is widely used, robust and reasonably accurate (ANSYS, 2006).

To validate the performance of a rear wing, the baseline performance of the vehicle had to be determined. A simplified 1:1 scale model was created of the 2014 University of Huddersfield Formula student vehicle. The 2014 vehicle was chosen because the current (2017) model was incomplete at the time of writing, and the 2014 model closely matched this year's intended dimensions. The assumption was made that minor details such as suspension geometry would not greatly impact the results of the study, and these have therefore been removed from the model for simplicity and to decrease computation time. The size of the flow domain was configured to match the scaling used by (Franck, Nigro, \& Storti, 2009) in their study of an Ahmed vehicle model (Figure 2). An inlet speed of $26.8 \mathrm{~m} / \mathrm{s}$ (60 mph) was chosen, as this is expected to be the maximum speed achievable during the events. An outlet static pressure of 0 Pa was applied. The free slip condition was applied to the flow domain boundary, which will result in the shear forces at the wall equal to 0 . The model which is the subject of the analysis is set as a wall, with the 'No Slip' 
condition applied. This will result in zero fluid velocity at the surface. Isothermal conditions were assumed and the fluid temperature set to default $25^{\circ} \mathrm{C}$. Each study used the $k-\varepsilon$ turbulence model with the convergence criteria set as a root mean square (RMS) residual target of 1.E-4.

\section{Figure 2}

Flow domain and named selections used in CFD study. Flow dimensions are 4,540, $3,027,30,270(X, Y, Z$ mm)

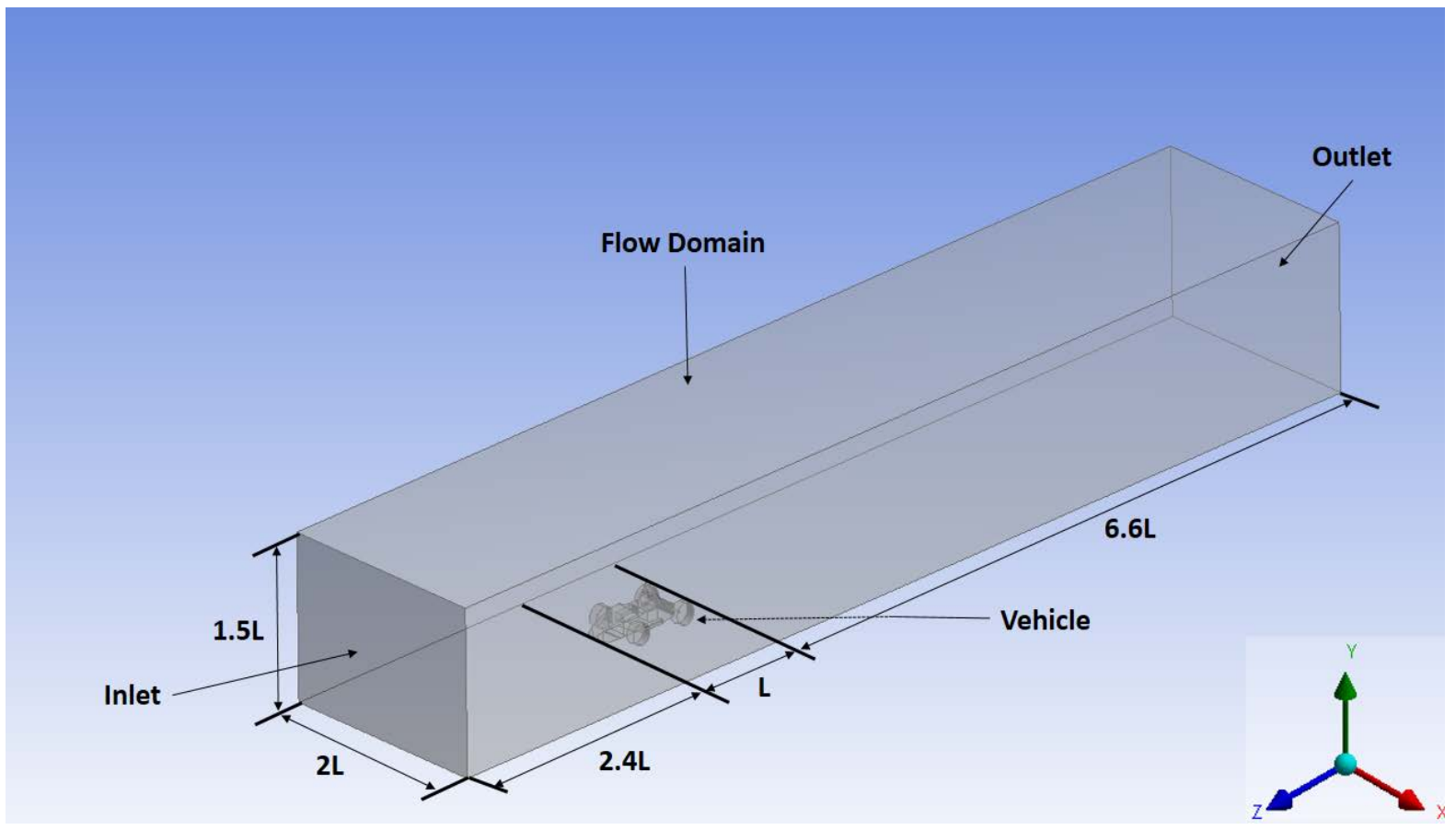

The mesh was generated using the integrated meshing tool available on ANSYS Workbench@. To improve the validity of the CFD results a mesh independence study was performed (Figure 5). Each mesh file used a default growth rate of 1.20. The final mesh file comprised of 933,024 elements with a minimum sizing of $4 \mathrm{~mm}$ to accurately model the complex geometry of the car (Figure 3 ). 


\section{Figure 3}

Final mesh corresponding to mesh independence study number 6 . Magnified image of the vehicle to illustrate the application of finer mesh around areas of high curvature, such as the roll bars and wheel axles

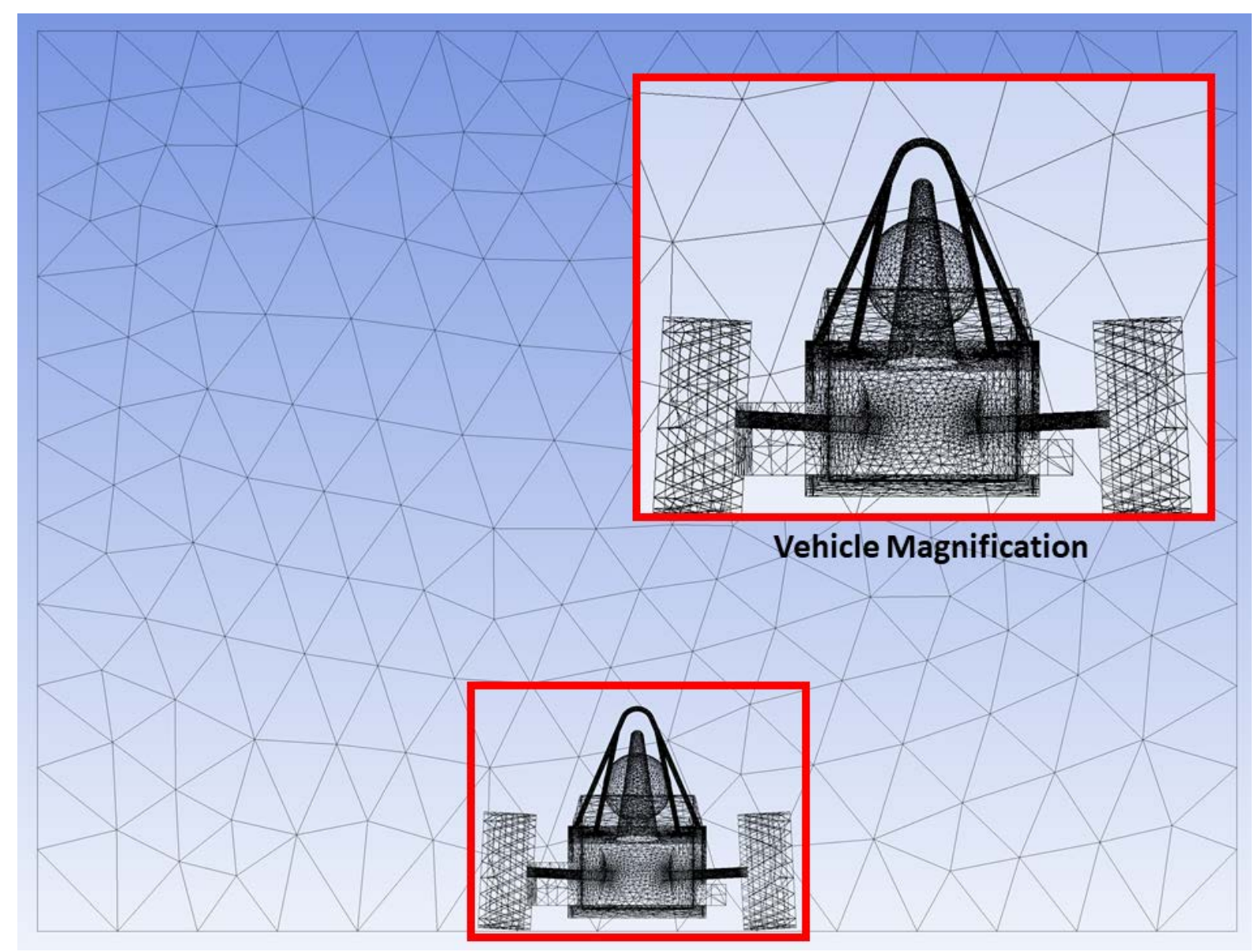

\section{Multiple-element wing configuration}

The amount of downforce a multi-element wing generates is a factor of many variables, and as such there are numerous ways to change the design to best suit the desired conditions. The multi-element wing is advantageous as, unlike singleelement wings, it can operate at higher angles of attack and thus achieve greater downforce. Work presented by McBeath (2006) describes guideline configurations 
for such designs. As downforce is a product of area, the maximum permissible chord length (c) and span (s) of $860 \mathrm{~mm}$ and $920 \mathrm{~mm}$ respectively were used. A threeelement design comprising a main element and two flaps was chosen as it was assumed to offer the benefits of a high lift configuration while keeping design complexity to a minimum (Figure 4). Research by Dahlberg (2014) investigated a number of high lift aerofoils and suggested that the E423 aerofoil would provide the best compromise of high lift characteristics to manufacturing ease.

\section{Figure 4}

Configuration of multiple-element (E423) rear wing with key variables of study a1 and $\alpha 2$. Chord length of main element set to $540 \mathrm{~mm}$, with Flap 1 \& 2 set at $180 \mathrm{~mm}$, overlap of Flap 1 and Flap 2 of $26.25 \mathrm{~mm}$ and gap of $20 \mathrm{~mm}$

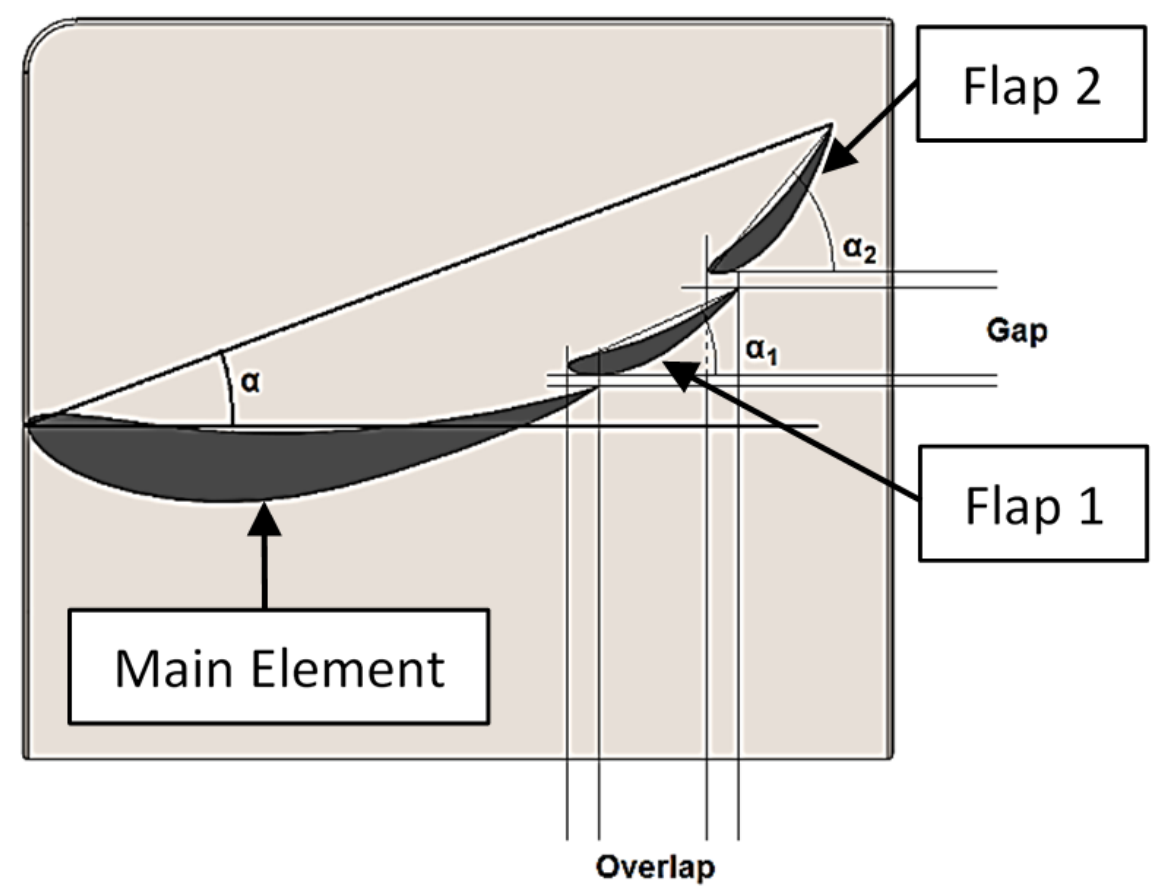

To achieve a highly efficient multiple-element design, many variables such as the angle of attack (AOA) of each element, gap and overlap need to be optimised for the specific requirements of the design. However, to produce a design in a suitable 
timeframe, suggested values of gap and overlap of $1-4 \% \mathrm{c}$ and $1-6 \% \mathrm{c}$ respectively (McBeath, 2006) were used and optimisation was focused on the AOA. Suggested values of AOA of trailing element are also presented by McBeath (2006), with angles of $25-30$ and 30-70 degrees for flap 1 and 2, respectively, expected to produce the highest levels of downforce. Six models were generated with a range of AOA (Table 2). The wing was tested in free-stream conditions with the same simulation parameters previously utilised in the baseline vehicle analysis. To save on computation time, symmetry was utilised, and thus the downforce values are half of the final full wing model. The assumption is made that the most efficient configuration in free-stream conditions will also be the most effective once implemented with the vehicle.

\section{Table 2}

Configuration of multiple-element rear wing consisting of three elements: main element, flap 1 and flap 2

\begin{tabular}{|l|r|r|r|}
\hline $\begin{array}{l}\text { Study } \\
\text { No. }\end{array}$ & $\begin{array}{l}\text { Flap 1 AOA } \\
\text { (degrees) }\end{array}$ & $\begin{array}{l}\text { Flap 2 } \\
\text { AOA } \\
\text { (degrees) }\end{array}$ & $\begin{array}{l}\text { Overall } \\
\text { AOA } \\
\text { (degrees) }\end{array}$ \\
\hline 0 & 20 & 20 & 13.80 \\
\hline 1 & 25 & 30 & 16.65 \\
\hline 2 & 26 & 40 & 18.73 \\
\hline 3 & 27 & 50 & 20.80 \\
\hline 4 & 28 & 60 & 22.81 \\
\hline 5 & 29 & 70 & 24.71 \\
\hline
\end{tabular}




\section{Results and discussion}

\section{Baseline vehicle analysis}

The change in lift and drag forces was recorded as the number of elements were increased (Figure 5). A relatively coarse domain enables quicker simulation time with acceptable result convergence ( $<5 \%$ for both lift and drag force values).

\section{Figure 5}

Convergence discrepancy of lift and drag forces against number of elements for baseline vehicle model

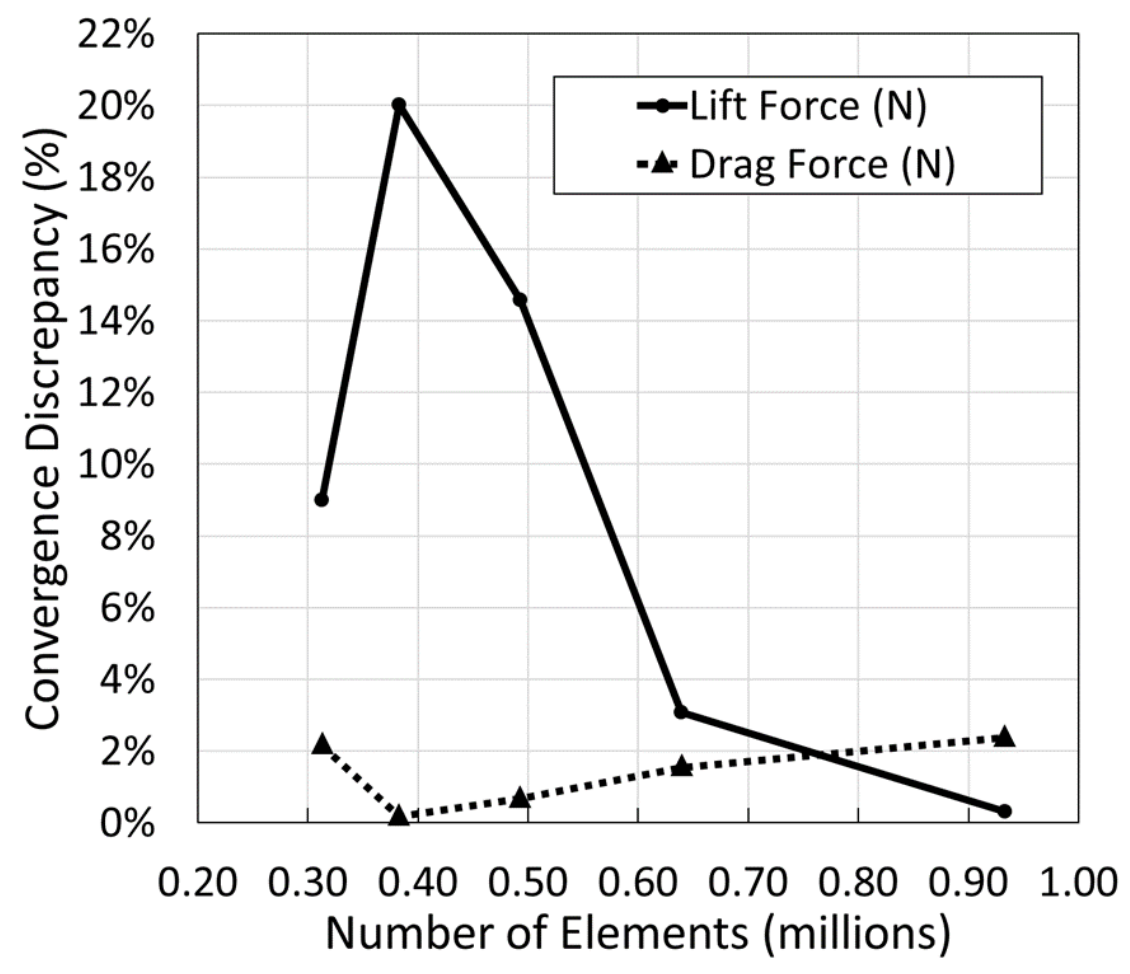

The inbuilt ANSYS Workbench@ post-processing tool was used to generate a visual display of the spatial distributions of pressure acting on the surface of the vehicle (Figure 6). Red regions on the tyres, nose and driver's head illustrate high pressures contributing to the drag force. It was evident from the post processing that the rear 
wing would benefit from being mounted as high as possible to avoid the disturbed flow from behind the driver's head, roll hoop and air intake.

\section{Figure 6}

Spatial pressure $(\mathrm{Pa})$ contour over the simplified vehicle surface

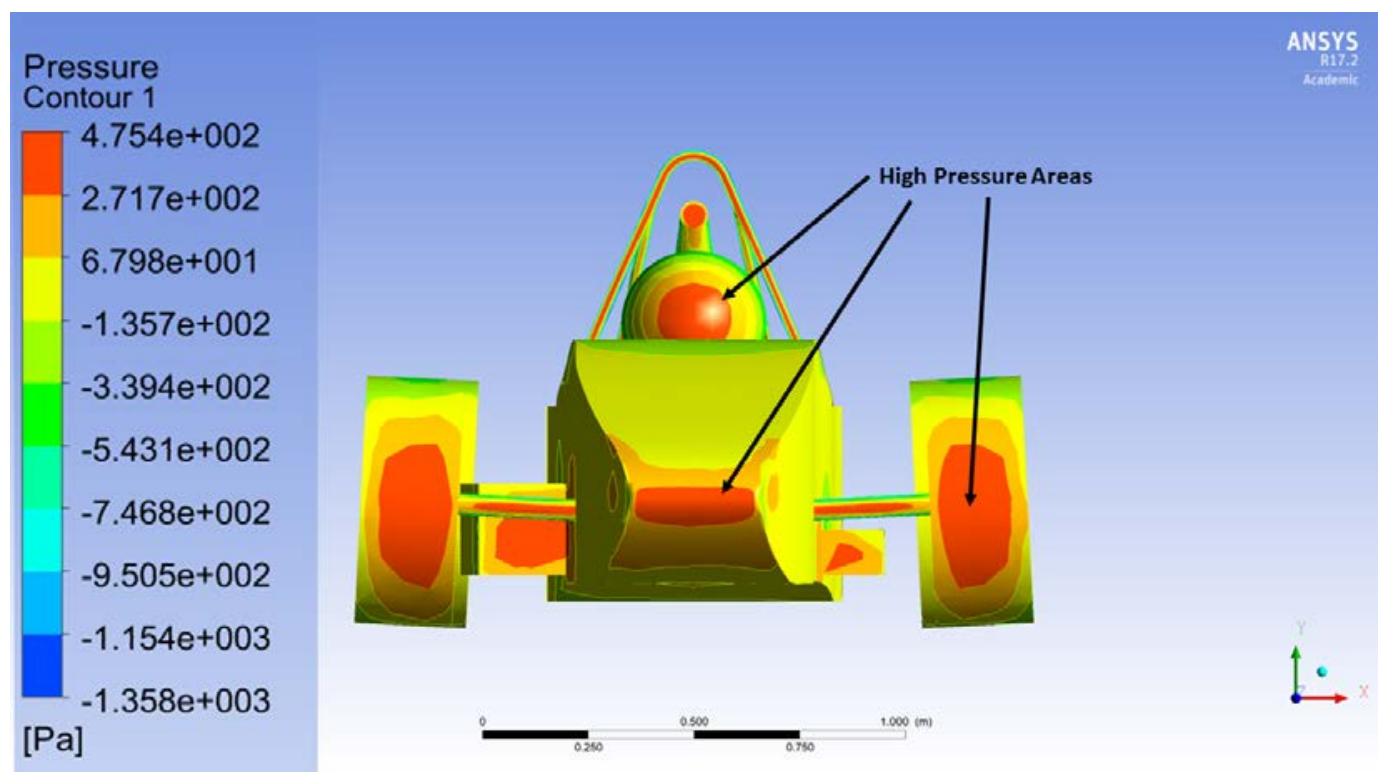

The coefficient of lift $\left(\mathrm{C}_{\mathrm{L}}\right)$ and coefficient of drag $\left(\mathrm{C}_{\mathrm{D}}\right)$ are dimensionless values which are used as an indication of a vehicle's aerodynamic performance. Using the force value acting on the vehicle in the $\mathrm{Z}$ axis of $277.6 \mathrm{~N}$, the resulting $C_{D}$ was calculated (Eq. 2).

$$
C_{D}=\frac{2 F}{\rho A V^{2}}
$$

where $F$ is the force acting on the vehicle body in the $Z$ axis, $\rho$ is the density of the fluid, $A$ is the frontal projection area which is used for calculating both drag and lift coefficients of vehicles $(K a t z, 1995)$ and $V$ is the vehicle velocity.

The baseline 2014 Formula Student vehicle with no aerodynamic devices displays a drag coefficient of $C_{D}=0.71$ and a positive lift coefficient of $C_{L}=0.21$. To validate the 
calculated coefficient of drag value, the result was compared to the experimentally obtained value of the Monash University FSAE 2005 vehicle, which gives a value of $C_{D}=0.83$ (Wordley \& Saunders, 2006), a similarity of 86\%. Although the cars are different in design, they do offer enough similarity to indicate that the CFD results obtained are in a close enough margin to justify the analysis configuration.

The vehicle analysis indicated that positive lift is generated, which for a race car is detrimental to its performance due to decreased stability at high speeds as well as a reduction in achievable cornering speed. The addition of aerodynamic devices generating downforce should, therefore, improve the performance of the car, making it more competitive in dynamic events.

\section{Rear wing performance}

Increasing the AOA of an aerofoil increases both the lift and drag forces generated. However, as the AOA increases, the flow becomes detached due to adverse pressure gradients (referred to as stall), resulting in a sudden reduction in lift. The downforce generated by the multi-element wing was recorded as a function of the overall AOA (Figure 7). The decline in downforce seen as the AOA reached 25 degrees is indicative of stall and, as such, would be unstable. Therefore, the configuration with an AOA of 22.81 degrees (Study No. 4) was chosen, as it is expected to provide the largest amount of downforce while avoiding stall. 


\section{Figure 7}

Downforce as a function of overall AOA

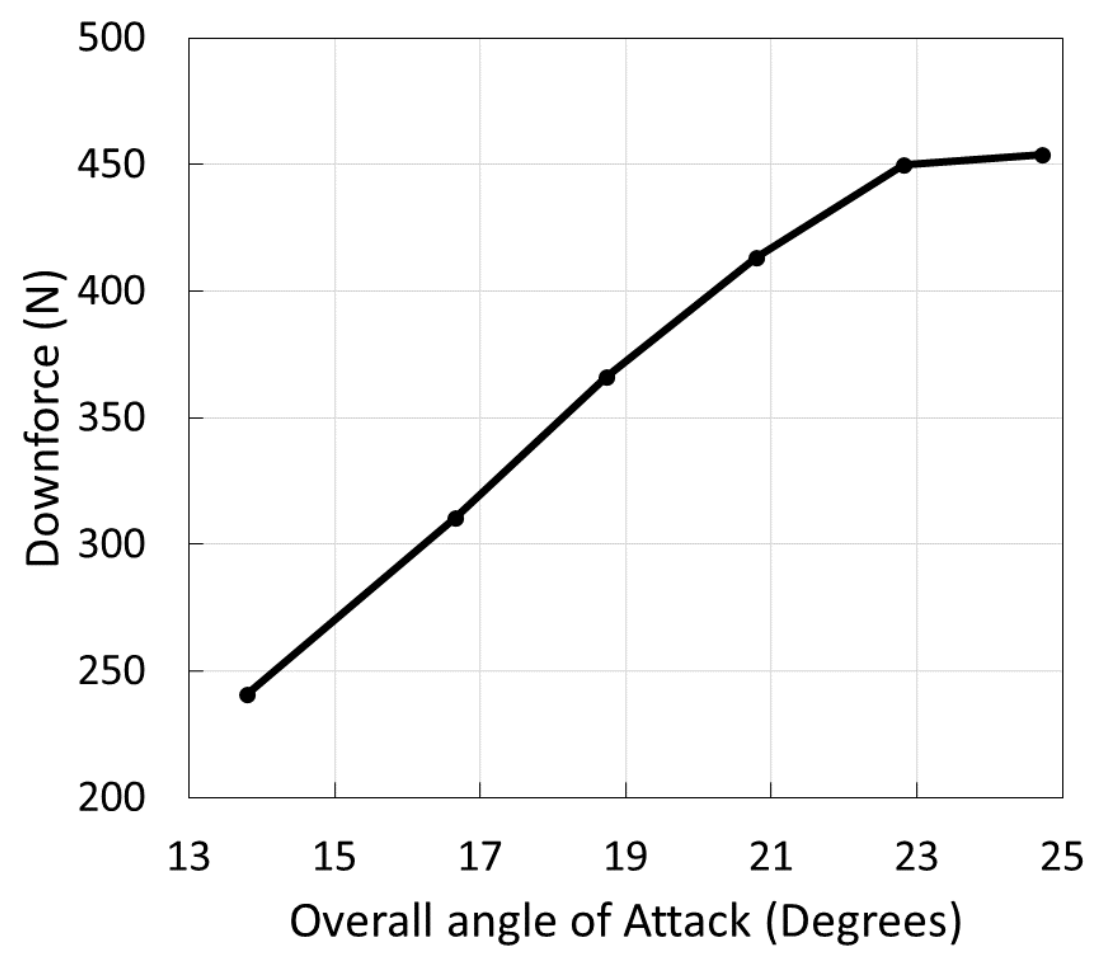

\section{Simplified model with implemented rear wing}

The optimised rear wing assembly was combined with the simplified vehicle model to evaluate the performance. The positioning of the rear wing was determined by setting the top of the end plates to be $1,200 \mathrm{~mm}$ from the ground, and the back face of the endplates to be $250 \mathrm{~mm}$ behind the rear wheels, ensuring regulation compliance. To account for the implemented rear wing, further mesh independence studies were performed with both the DRS open (low drag configuration) and DRS closed (high downforce configuration) (Figure 8). The simulation was configured with the same settings as the baseline vehicle model. The size of the domain was driven by the new vehicle length with the implemented wing of $3,277 \mathrm{~mm}$. The generated mesh used face sizing control of $0.02 \mathrm{~m}$ on the car and $0.01 \mathrm{~m}$ on the rear two elements of the wing. Face meshing was also applied to the rear two elements of the 
rear wing to avoid deformation aft of the aerofoil due to the complex geometry. The final mesh file contained 1,669,602 elements.

\section{Figure 8}

Mesh independence study of vehicle with implemented rear wing with the DRS closed (left) and DRS open (right)
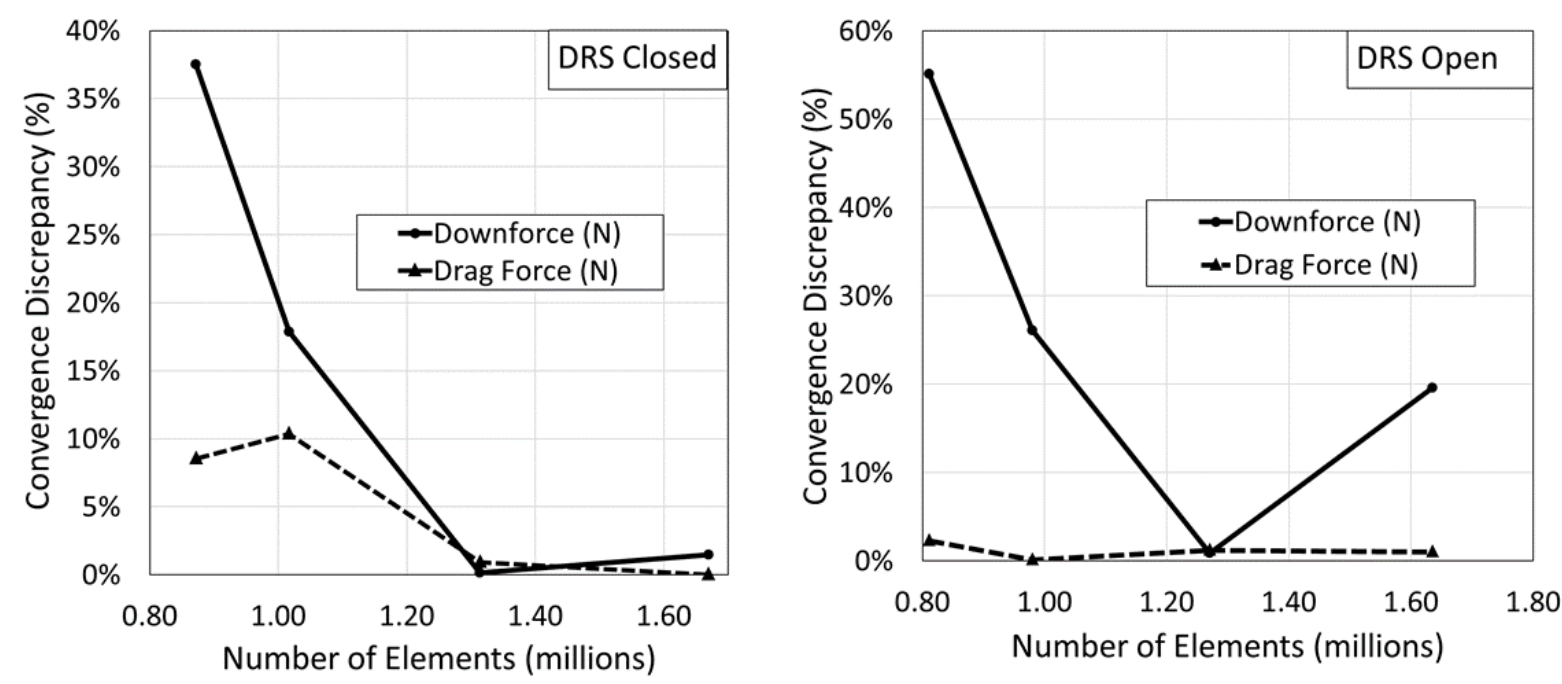

Although a higher level of convergence would be preferable for the downforce with the DRS open, limitations in computation power were causing excessively long computational time. However, as the primary focus of the DRS open configuration is the drag force, the results can be used as there was only a $1.0 \%$ discrepancy for this parameter.

The frontal projection area with the implemented rear wing in the DRS closed position was calculated to be $1.18 \mathrm{~m}^{2}$, and thus, with the recorded downforce and drag force values, the $C_{L}$ and $C_{D}$ were calculated to be 1.15 (acting in the negative $Y$ axis) and 1.21, respectively. The addition of the rear wing adds further areas of high pressure contributing to the vehicle's $C_{D}$ (Figure 9a). With the DRS open (Figure 9b), 
the frontal projection area is reduced to $0.99 \mathrm{~m}^{2}$. Using this area, the $C_{L}$ and $C_{D}$ were calculated to be 0.26 (acting in the negative $Y$ axis) and 0.79 , respectively.

\section{Figure 9}

Spatial pressure $(\mathrm{Pa})$ contour over vehicle surface with rear wing in both DRS closed

(a) and DRS open (b)

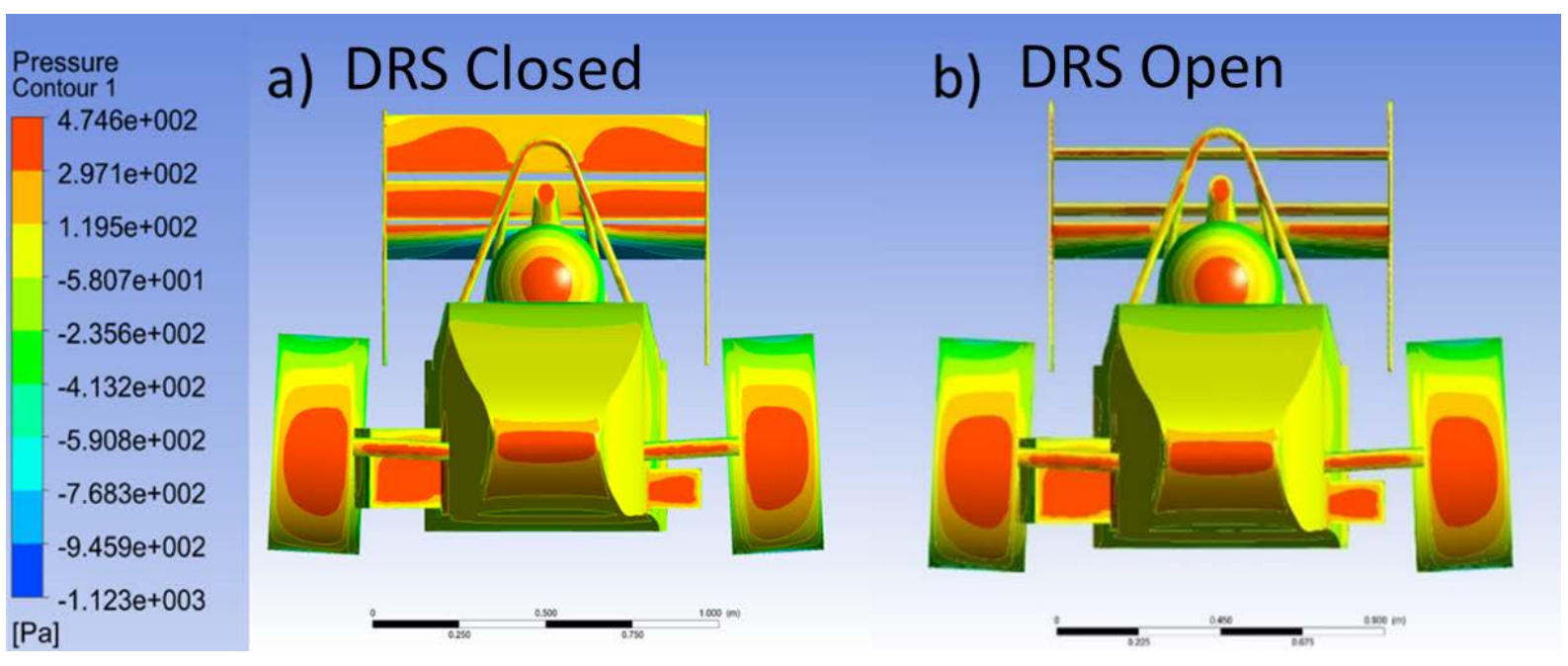

\section{Predicting vehicle performance with rear wing}

To determine the effectiveness of the implemented rear wing, the new vehicle characteristics were used to determine track performance with respect to the Formula student events. For simplicity, the effect of aerodynamic balance on stability was neglected at this stage, as the front wing was developed independently from this paper. The drag force as a function of velocity for the vehicle with the wing in both positions was generated (Figure 10). 
Figure 10

Drag force as a function velocity for the vehicle with the DRS open and closed

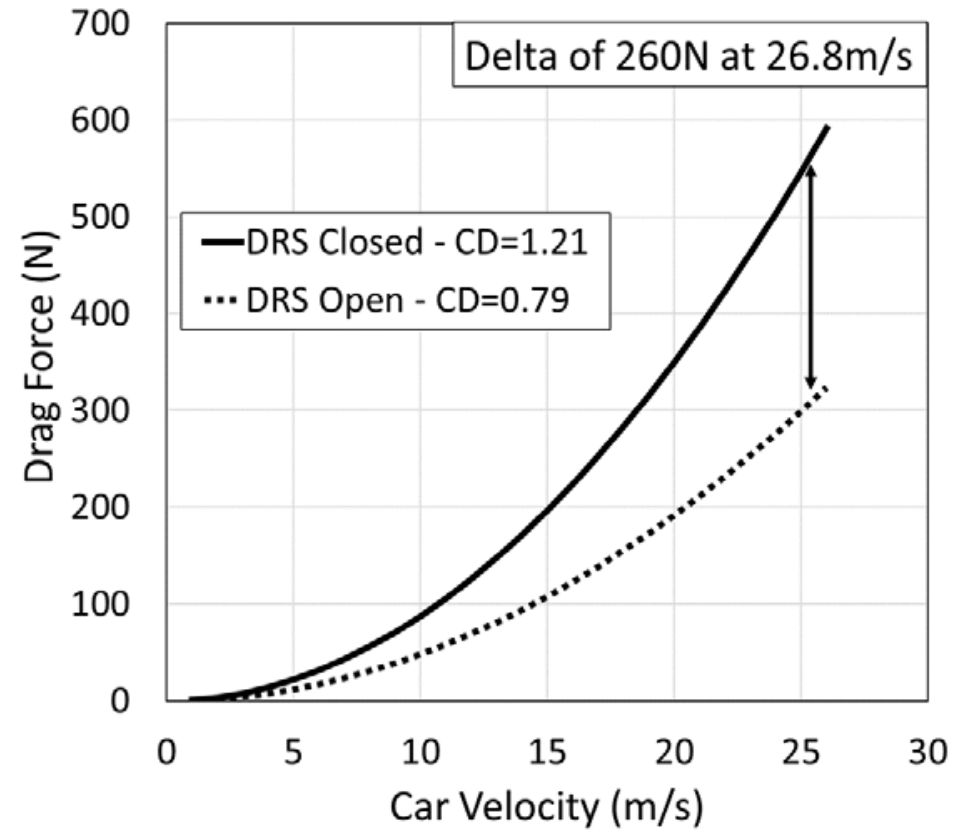

The resulting reduction in drag force was calculated to be $35 \%$ with the DRS open (Eq. 3).

$$
\Delta=\frac{F_{D R S-O p e n}-F_{D R S-C l o s e d}}{F_{D R S-O p e n}}
$$

\section{Cornering speed}

The calculation of maximum cornering speed is computed (Eq. 4). The value produced by this equation assumes that there is sufficient power to produce the maximum cornering speed. The limiting factors are that of the grip of the tires and CL.

$$
v_{\text {Max }}=\sqrt{\frac{m g}{\frac{m}{\mu r}-0.5 \rho A C_{L}}}
$$


where $m$ is the vehicle mass and $r$ is corner radius. The increased $C_{L}$ of the vehicle with implemented rear wing enabled quicker cornering speeds to be reached (Figure 11, left). As the corner radius increases, the maximum speed achievable differential between the two configurations becomes more apparent (Figure 11, right). The rear wing improved the theoretical maximum cornering speed by $3.1 \%$ for a corner radius of $13 \mathrm{~m}$.

\section{Figure 11}

Predicted cornering speed capabilities(left); speed difference between two configurations as a function of corner radius increases (right)
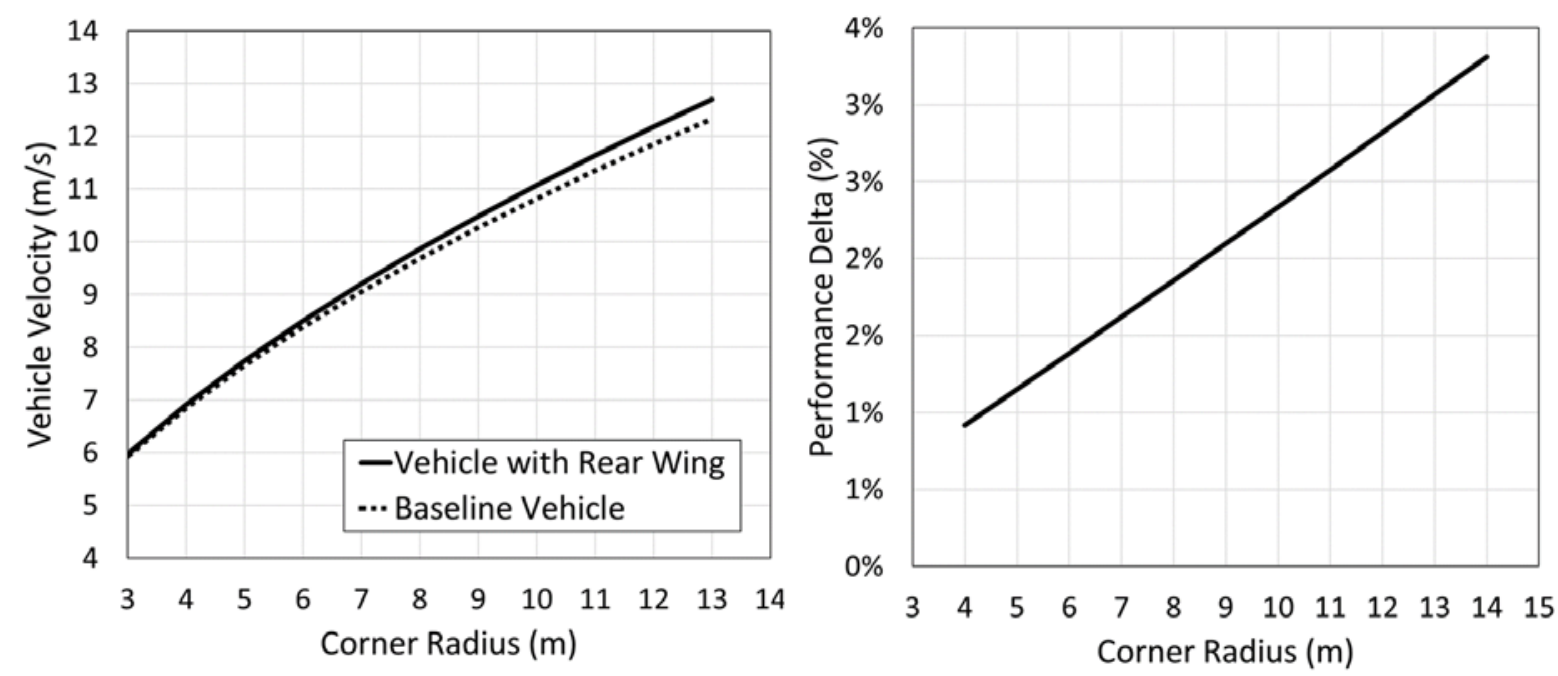

\section{Straight-line top speed}

Using the procedure described by McBeath (2006), the theoretical top speed can be calculated (Eq. 5). The equation has been modified to incorporate SI units as utilised by Wordley and Saunders (2006).

$$
V_{\operatorname{Max}(m / s)}=\sqrt[3]{\frac{P_{k W} \times 1633}{C_{D} A}}
$$


where $P_{k w}$ is the maximum engine power in $\mathrm{kW}$. For the baseline vehicle the maximum speed achievable is expected to be $53.62 \mathrm{~m} / \mathrm{s}$. For the vehicle with the rear wing in both the DRS open and closed positions, the top speeds are expected to be $49.94 \mathrm{~m} / \mathrm{s}$ and $40.86 \mathrm{~m} / \mathrm{s}$, respectively. The DRS open yields an $18.2 \%$ increase in straight-line speed potential compared to the closed configuration. However, top speeds are limited by the event design at student events and, as such, are not a key focus of aerodynamic design.

\section{Acceleration}

The dynamometer data from the KTM EXC 500 engine, which was acquired in 2012 by the Huddersfield Formula Student team, was combined with the gear ratios to determine the driving force acting at the wheels $\left(F_{w}\right)$. The initial driving force exceeds the available grip of the tyres, and thus the assumption is made that the friction force $\left(F_{f}\right)$ on the rear wheels will be the initial limiting factor of acceleration. At standstill $F_{f-}$ ${ }_{0}=\mu N$, where $\mu$ is the friction coefficient of the tyre and $N$ is the normal load. Thus, acceleration from standstill $\ddot{x}_{0}$ can be expressed as $\ddot{x}_{0}=F_{f-0} / m$. However, as the car begins to accelerate, additional load will be placed on the rear wheels, from the mass transfer $\left(P_{i}\right)$ and downforce $\left(F_{L}\right) . P_{i}$ is calculated as follows:

$$
P_{i}=\frac{m \ddot{x}_{i-1} h}{(a+b)}
$$

where $(a+b)$ equals the wheelbase and $h$ equals the distance from the ground to the vehicle's centre of gravity. As $P_{i}$ is used in calculating acceleration, the previous value of acceleration ( $\left.\ddot{x}_{i-1}\right)$ value is used. The assumption is made that the downforce generated acts only on the rear wheels and that the weight distribution is $35: 65$ front 
to rear. The simplifying assumption is also made that clutch slip and rolling resistance are negligible. Thus, the formula for calculating the frictional force of the rear tyres is as follows:

$$
F_{f}=\mu\left(0.65 m g \pm 1 / 2 \rho A C_{L} V^{2}+\frac{m \ddot{x}_{i-1} h}{(a+b)}\right)
$$

Again, using $\ddot{x}_{i}=F_{f} / m$, the acceleration can be calculated. As the driving force at the wheels becomes less than the friction force $\left(F_{f}>F_{W}\right)$ due to the increasing drag force $F_{D}$, the car becomes power limited in acceleration and the effects of the DRS becomes apparent. Power-limited acceleration $\left(\ddot{x}_{P}\right)$ can be expressed as follows:

$$
\ddot{x}_{P}=\frac{\left(F_{W}-F_{D}\right)}{m}
$$

Acceleration potential as a function of velocity was generated (Figure 12). Tyre friction coefficients $(\mu)$ of $0.8-1.2$ display the effects of traction-limited acceleration. As the vehicle speed increases, acceleration becomes power limited, and thus, the effects of DRS become apparent. 
Figure 12

Acceleration as a function of velocity

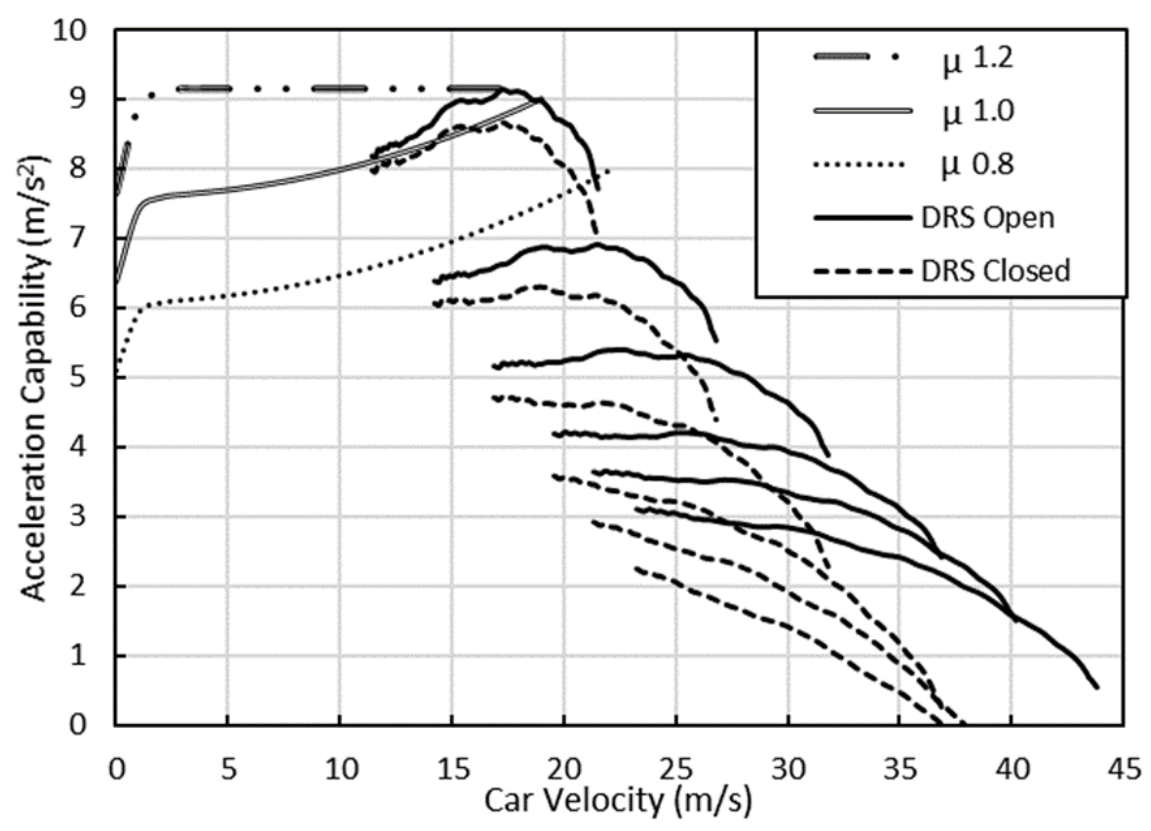

The acceleration potential increased by $15.7 \%$ at a velocity of $25 \mathrm{~m} / \mathrm{s}$ with the DRS open. In an attempt to predict and compare the performance over the $75 \mathrm{~m}$ acceleration event, an online FSAE vehicle simulator (FSAESim.com) was used with the inputted vehicle characteristics. The simulator predicted a time of $5.31 \mathrm{~s}$ and the result for the 2017 Hungary event was 5.49 s, a similarity of $96.7 \%$.

\section{Conclusions}

This paper used the computational fluid dynamics method to investigate the aerodynamic characteristics of the 2017 University of Huddersfield Formula Student vehicle with the implementation of a rear wing with incorporated DRS. It was expected that the addition of a rear wing should improve the vehicle's performance in 
dynamic events and that the DRS system should increase the vehicle's acceleration and top speed capabilities compared to the standard fixed wing configuration.

An initial investigation into the baseline performance of the vehicle was first performed to display the $C_{L}$ and $C_{D}$ values of 0.21 and 0.71 , respectively. The $C_{D}$ was then compared to wind tunnel test results from the Monash University team, revealing a similarity of $86 \%$. A multiple-element rear wing was configured and subsequently optimised to produce maximum downforce while avoiding stall. The baseline vehicle model was then used to generate two separate models, one with the incorporated wing in the standard configuration and the other with the wing in the DRS open configuration. The two models were then evaluated independently to find the aerodynamic characteristics for each configuration. With the wing in the DRS closed position, the $C_{L}$ and $C_{D}$ were found to be 1.15 and 1.21 , respectively, while the vehicle with the wing in the DRS open position had a $C_{L}$ and $C_{D}$ of 0.26 and 0.79 , respectively.

The obtained vehicle characteristics were then used to predict the dynamic performance with respect to the Formula Student event. The difference in drag force between the DRS open and closed configuration was first calculated to be $35 \%$. The maximum cornering speed as a function of radius was investigated for the baseline vehicle and the baseline vehicle with implemented rear wing in the closed position. The vehicle with implement wing with could take a $13 \mathrm{~m}$ radius corner $3.1 \%$ quicker than the baseline vehicle. The theoretical maximum straight-line speed was calculated for the baseline vehicle, baseline vehicle with rear wing and baseline vehicle with rear wing in the DRS open configuration, resulting in vehicle speeds of $53.62 \mathrm{~m} / \mathrm{s}, 40.86 \mathrm{~m} / \mathrm{s}$ and $49.94 \mathrm{~m} / \mathrm{s}$, respectively. The acceleration capabilities between the vehicle with the rear wing in DRS open and closed were determined. An 
increase in acceleration potential of $15.7 \%$ was observed for a velocity of $25 \mathrm{~m} / \mathrm{s}$ with the DRS open. Finally, the predicted time for the $75 \mathrm{~m}$ acceleration event was generated using an online simulator and compared to results obtained by the team in their 2017 Hungary event. The predicted time was $5.31 \mathrm{~s}$, whereas the recorded time was $5.49 \mathrm{~s}$, a similarity of $96.7 \%$.

The tracks designed for the Formula student events are usually short and comprise many corners in an attempt to minimise the top speeds achievable by the vehicles. Therefore, increased cornering speed due to the improved aerodynamics in addition to the DRS to enable quicker acceleration on the short straights would yield faster lap times and subsequently more points in the competition. The proposed design is expected to positively affect the aerodynamic characteristics of the 2017 vehicle, making it more competitive in the dynamic events. 


\section{Appendix 1}

\section{Nomenclature}

\begin{tabular}{|c|c|c|}
\hline Symbol & Description & Units (SI) \\
\hline A & Area & $\mathrm{m}^{2}$ \\
\hline$(a+b)$ & Wheelbase & $\mathrm{m}$ \\
\hline $\operatorname{AOA}(\alpha)$ & Angle of attack & Degrees \\
\hline $\mathrm{C}$ & Chord length & $\mathrm{m}$ \\
\hline$C_{D}$ & Coefficient of drag & Dimensionless \\
\hline$C_{L}$ & Coefficient of lift & Dimensionless \\
\hline $\mathrm{F}$ & Force & $\mathrm{N}$ \\
\hline 9 & Acceleration due to gravity & $\mathrm{m} / \mathrm{s}^{2}$ \\
\hline $\mathrm{h}$ & $\begin{array}{l}\text { Height from ground to } \\
\text { centre of gravity }\end{array}$ & $\mathrm{m}$ \\
\hline $\mathrm{m}$ & Mass & $\mathrm{kg}$ \\
\hline $\mathrm{P}$ & Pressure & $\mathrm{Pa}$ \\
\hline r & Radius & $\mathrm{m}$ \\
\hline $\mathrm{s}$ & Wing span & $\mathrm{m}$ \\
\hline $\mathrm{V}$ & Vehicle velocity & $\mathrm{m} / \mathrm{s}$ \\
\hline$\ddot{x}$ & Acceleration & $\mathrm{m} / \mathrm{s}^{2}$ \\
\hline$\mu$ & Coefficient of friction & Dimensionless \\
\hline$\rho$ & Density & $\mathrm{kg} / \mathrm{m}^{3}$ \\
\hline
\end{tabular}




\section{References}

ANSYS. (2006). ANSYS CFX-Solver Theory Guide: ANSYS CFX Release 11.0. [Software documentation].

Dahlberg, H. (2014). Aerodynamic development of Formula Student race car (Thesis). KTH Mechanics. Retrieved 27 November 2016 from http://urn.kb.se/resolve?urn=urn:nbn:se:kth:diva-148799

Franck, G., Nigro, N., \& Storti, M. (2009). Numerical Simulation of the Flow Around the Ahmed Vehicle Model. Latin American Applied Research, 39, 295-306. Retrieved 16 February 2017 from http://www.scielo.org.ar/scielo.php?script=sci_arttext\&pid=S032707932009000400003

IMechE. (2017a). History of Formula Student [web page]. Retrieved 14 September 2017 from https://www.imeche.org/events/formula-student/about-formulastudent/history-of-formula-student

IMechE. (2017b). The Formula Student Challenge [web page]. Retrieved 1 September 2017 from https://www.imeche.org/events/formula-student/aboutformula-student/the-challenge

Katz, J. (1995). Race Car Aerodynamics: Designing for Speed. Cambridge, MA: R. Bentley.

Leitl, P., Dürnberger, J. (2009). Using ANSYS CFX in Formula Student Racing, 2008 (July) [Unpublished paper].

McBeath, S. (2006). Competition Car Aerodynamics. Sparkford: Haynes. 
Merkel, J. P. (2014). Development of Multi-Element Active Aerodynamics for The Formula SAE Car. (Thesis). The University of Texas Arlington. Retrieved 23 November 2016 from https://uta-ir.tdl.org/uta-ir/handle/10106/24176

Versteeg, H. K., \& Malalasekera, W. (2007). An Introduction to Computational Fluid Dynamics: The Finite Volume Method (2nd ed.). Harlow: Pearson Prentice Hall.

Wordley, S., \& Saunders, J. (2006). Aerodynamics for Formula SAE: Initial Design and Performance Prediction. SAE World Congress, 2006(724), 2006-01-0806. doi:10.4271/2006-01-0806 